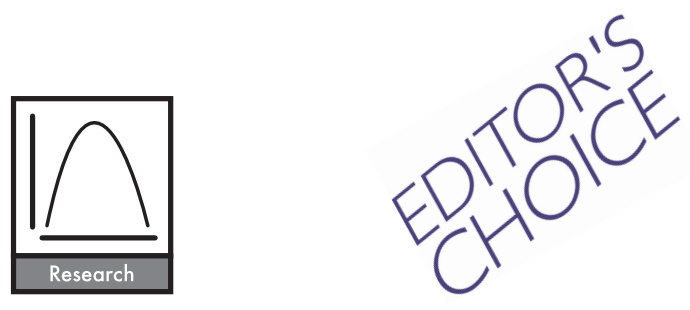

Ecography 36: 417-429, 2013

doi: 10.1111/j.1600-0587.2012.07669.x

(C) 2012 The Authors. Ecography (C) 2012 Nordic Society Oikos

Subject Editor: Joaquin Hortal. Accepted 27 July 2012

\title{
Quantifying island isolation - insights from global patterns of insular plant species richness
}

\author{
Patrick Weigelt and Holger Kreft \\ P. Weigelt (pweigel@uni-goettingen.de) and H. Kreft, Biodiversity, Macroecology and Conservation Biogeography Group, Univ. of Göttingen, \\ Büsgenweg 1, DE-37077 Göttingen, Germany.
}

\begin{abstract}
Isolation is a driving factor of species richness and other island community attributes. Most empirical studies have investigated the effect of isolation measured as distance to the nearest continent. Here we expanded this perspective by comparing the explanatory power of seventeen isolation metrics in sixty-eight variations for vascular plant species richness on 453 islands worldwide. Our objectives were to identify ecologically meaningful metrics and to quantify their relative importance for species richness in a globally representative data set. We considered the distances to the nearest mainland and to other islands, stepping stone distances, the area of surrounding landmasses, prevailing wind and ocean currents and climatic similarity between source and target areas. These factors are closely linked to colonization and maintenance of plant species richness on islands. We tested the metrics in spatial multi-predictor models accounting for area, climate, topography and island geology. Besides area, isolation was the second most important factor determining species richness on the studied islands. A model including the proportion of surrounding land area as the isolation metric had the highest predictive power, explaining $86.1 \%$ of the variation. Distances to large islands, stepping stone distances and distances to climatically similar landmasses performed slightly better than distance to the nearest mainland. The effect of isolation was weaker for large islands suggesting that speciation counteracts the negative effect of isolation on immigration on large islands. Continental islands were less affected by isolation than oceanic islands. Our results suggest that a variety of immigration mechanisms influence plant species richness on islands and we show that this can be detected at macro-scales. Although the distance to the nearest mainland is an adequate and easy-to-calculate measure of isolation, accounting for stepping stones, large islands as source landmasses, climatic similarity and the area of surrounding landmasses increases the explanatory power of isolation for species richness.
\end{abstract}

The discrete, isolated nature of islands makes them useful units for evolutionary and ecological studies (Whittaker and Fernández-Palacios 2007), and has enabled island biogeography to contribute considerably to the development of theory on the origin and the maintenance of species richness (Lomolino and Brown 2009). According to the equilibrium theory of island biogeography, species richness on islands results from a dynamic equilibrium between the opposing processes of immigration and extinction (MacArthur and Wilson 1967). Assuming immigration to happen more frequently on less isolated islands, MacArthur and Wilson considered isolation as one of the main factors influencing species richness. Although these authors considered the importance of evolutionary processes, they excluded phylogenetic diversification from the equilibrium theory, arguing that speciation becomes important only on the largest and most isolated islands. More recent models have emphasized the role of evolutionary processes at large time scales for the assembly and species richness of biota on oceanic islands. According to Whittaker et al. (2008), oceanic islands show varying rates of immigration, speciation and extinction over time when emerging from volcanic activity or submerging from erosion. In fact, speciation may act on the same time scale and be of similar quantitative importance for species richness as immigration and extinction (Heaney 2000, Carroll et al. 2007) as evidenced by the high degree of insular endemism (Kier et al. 2009).

The principal effect of isolation on species richness results from an inverse relationship with the probability of dispersal to an island, influencing the chance of colonization (MacArthur and Wilson 1967). Particularly on small and less isolated islands, the continuous arrival of propagules might in addition increase population viabilities of species present on the island via a 'rescue effect' (Brown and Kodric-Brown 1977). Consequently, overall species richness should be negatively correlated to island isolation. However, the effect of isolation on large islands is decreased by a 'target area effect', i.e. large islands receive more immigrants (Whitehead and Jones 1969). Furthermore, gene flow between source and island populations should be negatively correlated to isolation, leading to a higher probability of speciation on remote islands (Heaney 2000). Especially on large and heterogeneous 
islands, cladogenesis (in situ speciation; Stuessy et al. 2006) thus counteracts the negative effect of isolation on immigration (Heaney 2000, Losos and Schluter 2000, Kisel and Barraclough 2010).

Many empirical studies have investigated the effect of isolation on species richness for various taxa and from local to global scales. Most studies have found strong support for the expected negative relationship (Johnson and Simberloff 1974, Kalmar and Currie 2006, Kreft et al. 2008). Others have found little or no significant effect of isolation (Abbott 1978, Price 2004, Cody 2006), particularly when study systems were of limited spatial extent and exhibited little variation in isolation (reviewed by Whittaker et al. 2001).

While conceptual models in island biogeography commonly consider isolation as the 'distance to', or more generally as 'isolation from' an unspecified source pool, correlative studies require a precise metric quantifying isolation. Many different metrics have been tested. The vast majority of studies have used the distance between a target island and the nearest mainland coast (Case 1975, Abbott 1978, Chown et al. 1998) since continental landmasses harbour large species pools for potential island colonization. The validity of this approach is supported by phylogenetic studies indicating long-distance dispersal events from continents to even remote islands (Alsos et al. 2007, Harbaugh and Baldwin 2007). However, islands may also serve as sources for immigration to other islands and to the mainland (Bellemain and Ricklefs 2008, Keppel et al. 2009). The distance to the nearest island (Johnson and Simberloff 1974), the nearest large or larger island (McMaster 2005), the nearest older island (Cardoso et al. 2010), or the mean distance to other islands (Borges and Hortal 2009) have therefore been used in correlative studies. The UNEP isolation index (Dahl 2004), another frequently used metric (Boyer and Jetz 2010, Kisel and Barraclough 2010), incorporates the distances to the nearest mainland, nearest island group and nearest equally sized or larger island. However, nearest landmasses are not necessarily suitable source areas because colonization also depends on the favourability of island environmental conditions, especially on climate (Steinbauer et al. 2012). Price (2004) therefore used the distance to the nearest island with analogous habitats as isolation metric. Moreover, long-distance dispersal depends on dispersal vectors and is influenced by wind and ocean currents (Muñoz et al. 2004). To account for this, Diver (2008) used the distance to the nearest upwind landmass. Similarly, Abbott (1974) found the distance to the nearest landmass in a westerly direction to be a strong predictor of plant species richness for a set of islands within the west wind zone of the southern hemisphere.

MacArthur and Wilson (1967) proposed that the spatial arrangement of islands should affect species richness. Stepping stones, i.e. islands located between the source and the target area that are smaller than the source landmass (Gilpin 1980), should facilitate island colonization. Phylogenetic data on various groups of organisms have provided evidence for directional colonization of several archipelagos in the order of island formation (Garb and Gillespie 2006, Díaz-Pérez et al. 2008). In order to account for stepping stones, the shortest over-water distance (Kalmar and Currie 2006) or the largest gap (Diver 2008) along stepping stone paths have been used. Furthermore, the potential for immigration increases with source landmass area (Taylor 1987). In contrast to isolation metrics measured as distances to one specific source, some metrics account for this phenomenon by integrating all landmasses surrounding an island. Weighted by their distances, the areas of surrounding islands sum up to the neighbour index by Kalmar and Currie (2006). Accordingly, this and similar metrics (Thornton 1967, Cody 2006) account for island position within an archipelago. Moreover, source landmass geometry is a potentially important factor. Taylor (1987) argued that islands off straight-line shores have higher immigration rates than islands off peninsulas. Source landmass area within defined radii around the target island can thus be quantified to account for coastline shape and the amount of available source area (Diver 2008).

Given the complexity of island isolation in general and the wide variety of ways it has been quantified in particular, it is surprising that no attempts have been made at comprehensive comparisons of isolation metrics at large spatial scales. Here, we revisit island isolation as a central issue in biogeography. We formalise the concepts and metrics just reviewed and supplement them with a series of novel metrics representing different aspects of island isolation. Our objectives are to identify ecologically meaningful metrics and to quantify their relative importance in determining global-scale island biogeographic patterns. We use contemporary vascular plant species richness as response variable, but expect the presented isolation metrics to be relevant also to other biogeographic patterns. We hypothesize that the proportion of variation in species richness explained by isolation can be increased by considering large source islands, stepping stones, climatic similarity, wind and ocean currents and the area of surrounding landmasses, as opposed to considering the distance to the nearest mainland only.

\section{Methods}

\section{Species richness, geographic reference and abiotic data}

In order to evaluate the effects of different aspects of isolation on the species richness of island floras we built on data and statistical models from Kreft et al. (2008). These models account for island area, isolation (distance to nearest mainland), topography, climate and geology as predictors of species richness of native vascular plants for a set of 488 islands worldwide. Species numbers were based on a comprehensive review of island floras, checklists and compilations (Supplementary material Appendix 10). To reduce bias potentially introduced by varying sampling effort and inventory incompleteness (compare Santos et al. 2010), we excluded studies of obvious low quality. However, we acknowledge that even for well-known island floras checklists are rarely complete. To what extent this may influence macroecological analyses at a global scale, cannot be estimated with sufficient accuracy at present. Islands 
were defined as landmasses smaller than Australia surrounded by ocean. As geographic reference, we used the GADM database of global administrative areas (GADM ver. 1; Hijmans et al. 2009), that contains $>85000$ highresolution landmass polygons. For eight islands that could not be assigned to any GADM polygon, a polygon was drawn according to maps in the original publications or digital elevation data at $90 \mathrm{~m}$ resolution (Jarvis et al. 2008). Large island groups (more than three comparably large islands; e.g. Svalbard) were excluded to avoid issues arising from conceptual differences between single islands and archipelagos. The resulting data set comprised a global selection of 453 islands, small island groups and atolls (Supplementary material Appendix 1). Island area $\left(\mathrm{km}^{2}\right)$ as well as latitude and longitude of the mass centroid were calculated for each polygon. Island geology data (continental, volcanic or atoll) were adopted from Kreft et al. (2008). Mean annual temperature $\left({ }^{\circ} \mathrm{C}\right)$, annual precipitation $\left(\mathrm{mm} \mathrm{yr}^{-1}\right)$ and elevational range $(\mathrm{m})$ were extracted from WorldClim (Hijmans et al. 2005). For islands not covered by WorldClim, literature values were taken from Kreft et al. (2008). Species richness, area, precipitation, temperature (plus fifty) and elevational range (plus one) were $\log _{10}$-transformed before analysis. GIS analyses were performed in ArcGIS/ArcINFO Desktop 9.3.1 (ESRI, Redlands). Statistical analyses were run in R 2.12.0 (R Development Core Team).

\section{Isolation metrics}

We distinguished five isolation components (Table 1): 1) distance, 2) stepping stone distance, 3) distance modified by wind and ocean currents, 4) stepping stone distance modified by wind and ocean currents and 5) surrounding landmass area. These components represent different modes of isolation between a target island and potential species pools. Within the isolation components, we considered different potential source pools: mainland only, all landmasses exceeding a certain minimum area, climatically similar mainland only and all climatically similar landmasses exceeding a certain minimum area. We calculated seventeen conceptually different isolation metrics, with sixty-eight variations in total (Fig. 1, Table 1) and classified each isolation metric by isolation component and source pool. See Supplementary material Appendix 2 for a detailed description of the metric calculations and underlying hypotheses. Values of twenty-eight metric variations for all 453 islands are provided in Supplementary material Appendix 9.

\section{1) Distance}

All distances were calculated using an azimuthal equidistant map projection centred individually for each target island. We calculated the shortest distance from an island's mass centroid $\left(\mathrm{D} 1 \mathrm{a}_{\mathrm{m}}\right)$ and its coastline $\left(\mathrm{D} 1 \mathrm{~b}_{\mathrm{m}}\right)$ to the nearest mainland and the distance from an island's coastline to the nearest landmass exceeding a certain area threshold $\left(\mathrm{D}_{2}\right)$. Area thresholds were varied systematically from $10^{0}$ to $10^{5} \mathrm{~km}^{2}$ and from one to ten times the area of the target island. Distances to climatically similar mainlands $\left(\mathrm{D} 4_{\mathrm{cm}}\right)$
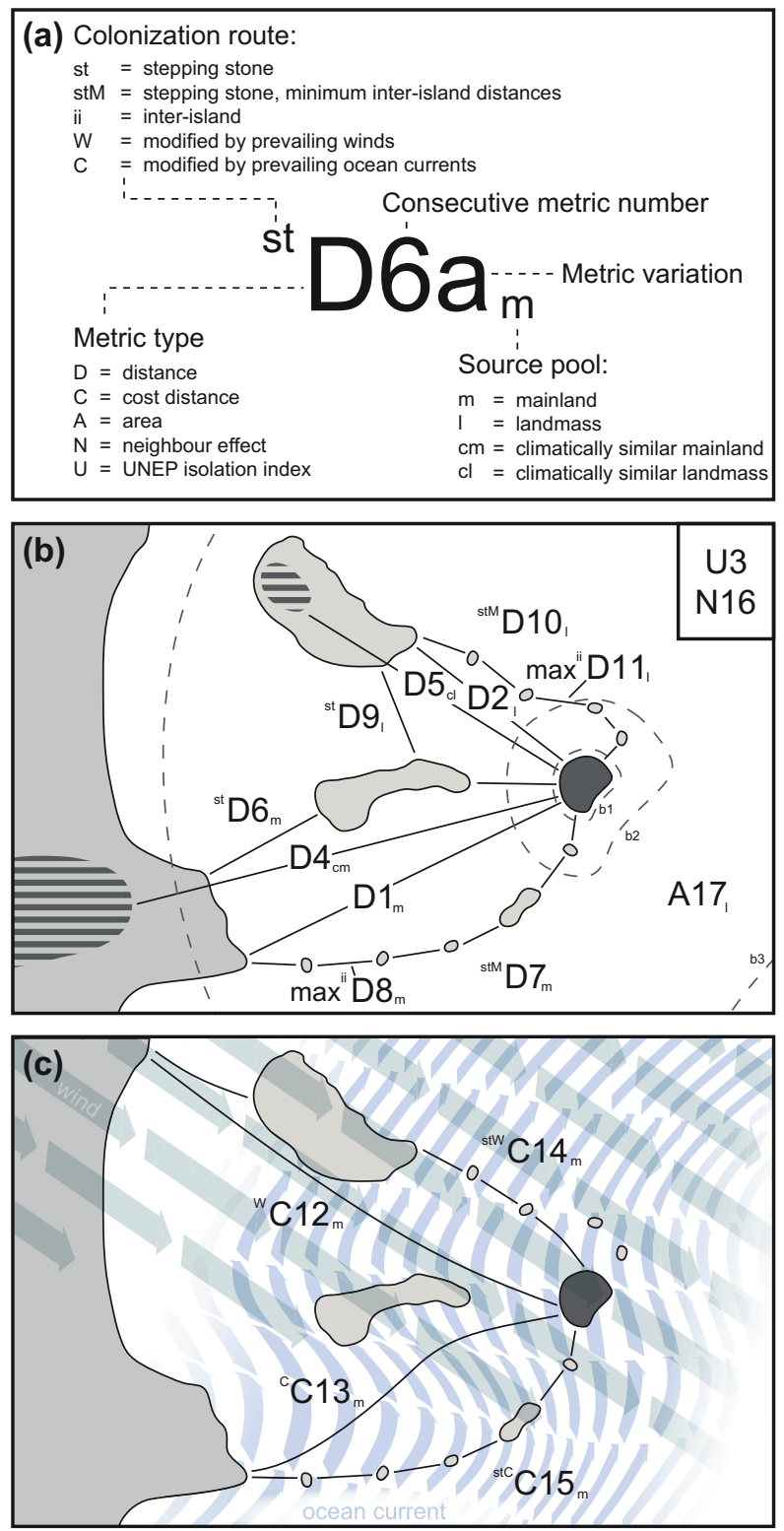

Figure 1. (a) Symbology for isolation metrics used in this study. (b-c) Schematic representation of hypothesized island immigration pathways of seventeen tested isolation metrics. These metrics reflect (b) measures of geographic distance, stepping stone distance, and surrounding landmass area as well as (c) the influence of prevailing winds (straight grey arrows) and ocean currents (curved blue arrows). In both (b) and (c), the target island is coloured dark grey; the mainland is located on the left. $\max ^{\mathrm{ii}} \mathrm{D} 8_{\mathrm{m}}$ and $\max ^{\mathrm{ii}} \mathrm{D} 11_{1}$ refer to the longest inter-island distance along a stepping stone

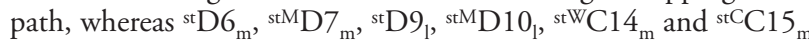
refer to the full path between source landmass and target island. In (b), hatched regions indicate areas climatically similar to the target island. $b_{1}$ to $b_{3}$ indicate buffer zones around the target island for calculation of surrounding landmass proportions (A17 $)$. Metrics U3 and N16 are not shown graphically.

and landmasses $\left(\mathrm{D} 5_{\mathrm{cl}}\right)$ were calculated similarly. As sources, we considered areas resembling the climatic space of the target island based on WorldClim (Hijmans et al. 2005), i.e. mean annual temperature deviating no more than $2^{\circ} \mathrm{C}$ from the range of mean annual temperatures on the target 


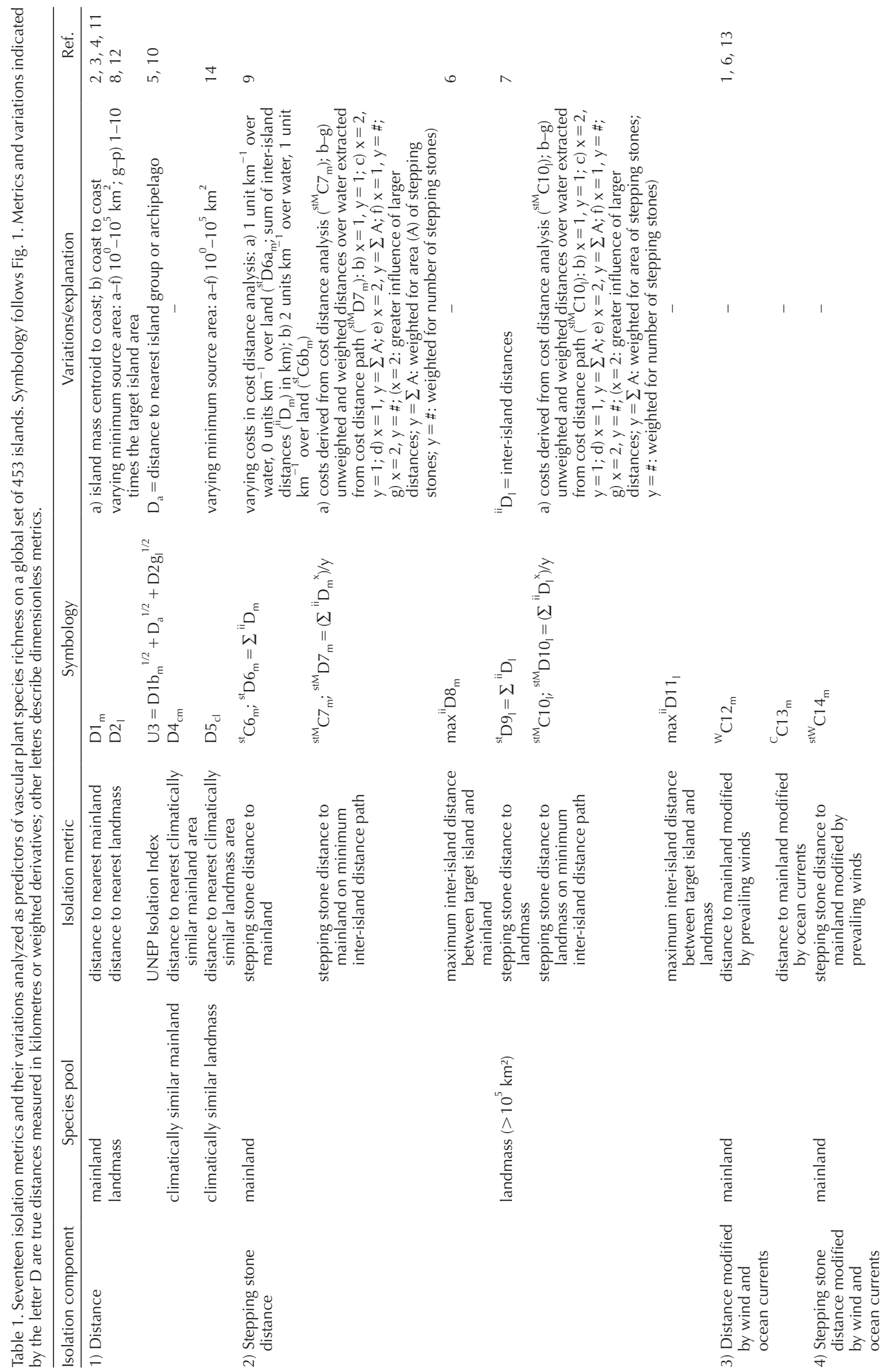


island and annual precipitation being not more than $20 \%$ lower than the minimum and not more than $20 \%$ higher than the maximum annual precipitation on the target island. These thresholds were chosen arbitrarily to exceed the climatic range of the target island by a reasonable degree. Values of the UNEP isolation index (U3) were obtained from the UNEP Island Directory (Dahl 2004) for 229 islands. Missing values were calculated as the sum of square roots of the distances to the nearest equally sized or larger island, the nearest island group or archipelago and the nearest continent (Dahl 2004).

\section{2) Stepping stone distance}

We calculated two different types of stepping stone distances, both as the least accumulative cost distances from the nearest source area to a particular target island. Cost distance analysis is a powerful tool in geographical analyses and can, e.g. be used to find the most economic route for a highway through a hilly region. Here, we applied cost distance analysis to estimate the potential immigration pathway between two landmasses crossing a cost surface consisting of open water and potential stepping stone islands. All islands of at least $1 \mathrm{~km}^{2}$ were considered as possible stepping stones. First, we minimized the accumulative over-water distance between target island and source area. Costs were defined as either one unit per kilometre over water and zero units per kilometre over land (over-water distance in kilometres) or two units per kilometre over water and one unit per kilometre over land. The source was either defined as the mainland $\left({ }^{\text {st }} \mathrm{D} 6_{\mathrm{m}}\right)$ or as a landmass of at least $100000 \mathrm{~km}^{2}\left({ }^{\text {st }} \mathrm{D} 9_{1}\right)$, which was the most important source area size class among the distance to landmass (D2 $)$ variations. Second, we computed a stepping stone pathway of minimized inter-island distances by applying costs of one unit per kilometre over land and linearly increasing costs with increasing distance to landmass over water. This was again calculated for mainland $\left({ }^{\mathrm{stM}} \mathrm{D} 7_{\mathrm{m}}\right)$ and landmass of at least $100000 \mathrm{~km}^{2}\left({ }^{\mathrm{stM}} \mathrm{D} 10_{1}\right)$ as source area. Area and number of stepping stones were used in the calculation of weighted stepping stone distances. The maximum step length was extracted from the pathway to the nearest mainland $\left(\max { }^{\mathrm{ii}} \mathrm{D} 8_{\mathrm{m}}\right)$ and the nearest landmass of at least $100000 \mathrm{~km}^{2}\left(\max { }^{\mathrm{ii}} \mathrm{D} 11_{1}\right)$.

\section{3) Distance modified by wind and ocean currents}

We accounted for wind $\left({ }^{\mathrm{W}} \mathrm{C} 12_{\mathrm{m}}\right)$ and ocean currents $\left({ }^{\mathrm{C}} \mathrm{C} 13_{\mathrm{m}}\right)$ by incorporating their prevailing directions as horizontal factors in cost distance analyses. Horizontal ocean current directions at the water surface (derived from NASA ECCO2; Menemenlis et al. 2008) and wind directions at water and land surfaces (derived from NCEP/ NCAR; Kistler et al. 2001) were averaged over ten years. Costs were set to one unit per kilometre irrespective of the crossed medium (i.e. land or water).

\section{4) Stepping stone distance modified by wind and ocean currents}

We calculated stepping stone distances considering wind $\left({ }^{\text {stW }} \mathrm{C} 14_{\mathrm{m}}\right)$ and ocean currents $\left({ }^{\mathrm{stC}} \mathrm{C} 15_{\mathrm{m}}\right)$ as in section 3, except that costs were defined as one unit per kilometre over water and zero units per kilometre over land. 


\section{5) Surrounding landmass area}

We applied two different approaches to assess the effect of surrounding landmasses on the focal islands. The neighbour index (N16), proposed by Kalmar and Currie (2006), is the sum of the areas of all surrounding islands closer than the nearest mainland inversely weighted by their squared distances to the focal island. We calculated the neighbour index in its original form as well as variations including all islands or all landmasses (raw or log-transformed area). In addition, we computed the proportion of land area in the surrounding of the target island within buffer distances of $10^{0}$ to $10^{4} \mathrm{~km}\left(\mathrm{~A} 17_{1}\right)$. As additional metric variations, we summed up the landmass proportions in all possible combinations of two to five consecutive buffer zones. This metric accounts for the coastline shape of large landmasses by including only the area of the part that extends into a certain buffer.

\section{Statistical analysis}

We computed single-predictor regression models with the number of vascular plant species per island $\left(\log _{10^{-}}\right.$ transformed) as the response variable and each isolation metric in turn as the explanatory variable. We then used multi-predictor models including island area, annual mean temperature, annual precipitation, elevational range, geology and one isolation metric variation at a time to assess the explanatory power of each metric variation after accounting for abiotic factors shown to significantly influence species richness on islands (Kreft et al. 2008). Best variations of each isolation metric were chosen based on the Akaike information criterion (AIC) values of the multipredictor models. These seventeen best metric variations were used for further analyses. We tested all possible combinations of two or more of these best isolation metric variations in the multi-predictor framework and assessed relative model support using AIC. Pairs of models with $\triangle \mathrm{AIC}<2$ were considered as receiving equal statistical support (Burnham and Anderson 2002). In order to avoid issues arising from multi-collinearity, we considered only combinations of metrics that were not strongly correlated $(r<0.7)$. Second order interactions between area and isolation metrics were added to the best candidate models including one or more isolation metrics. Non-significant interaction terms were dropped. Isolation metrics entered the analyses both as raw variables and $\log _{10}$-transformed after adding 0.5 to avoid taking the logarithm of zero. Additionally, N16c entered the analyses $\log _{10}$-transformed twice since its frequency distribution was still strongly skewed after the first transformation.

To account for significant spatial autocorrelation in the model residuals of generalized linear models (GLM) we performed spatial simultaneous autoregressive models (SAR) of the error type using the R-package spdep (Bivand et al. 2011). SARs of the error type model the effect of spatial autocorrelation in the error term by means of a weighted neighbourhood matrix (Bivand et al. 2011). This avoids type I error inflation and biased parameter estimates due to autocorrelation (compare Dormann et al. 2007). We adopted the neighbourhood structure (lag distance of
$1000 \mathrm{~km}$ ) and weighting (row-standardization) from Kreft et al. (2008), empirically optimized following Kissling and Carl (2008). Patterns of spatial autocorrelation in model residuals were assessed with Moran's I correlograms and global Moran's I values. Applying spatial models significantly reduced spatial autocorrelation in model residuals (Supplementary material Appendix 8) and consistently improved model fits. Results from non-spatial GLMs are shown in Supplementary material Appendix 5, 6 and 7. We used GLMs of the Gaussian family because they consistently outperformed GLMs of the Poisson family in terms of model fit (AIC) and model diagnostics (Crawley 2007) in spite of count data as raw response variable. Homoscedasticity and normality of the residuals were evaluated with plots of standardized residuals against fitted values and QQ plots.

We calculated pseudo- $R^{2}$ values for SAR models as the squared Pearson correlation coefficients between fitted and observed values (Kissling and Carl 2008). For nonspatial models, the pseudo- $\mathrm{R}^{2}$ equals the ordinary least squares $R^{2}$. Fitted values of SAR models can be partitioned additively into trend (non-spatial smooth) and signal (spatial smooth). We calculated both a pseudo- $\mathrm{R}^{2}$ for the fitted values including the spatial component (hereafter $\mathrm{R}_{\mathrm{sp}}^{2}$ ), and a pseudo- $\mathrm{R}^{2}$ for the trend excluding the spatial component, which represents the part of the variation explained by the predictors (in the context of SAR models hereafter $\mathrm{R}^{2}$ ).

We calculated the relative importance of each isolation metric in the multi-predictor models using the metric 'pmvd' in the R-package relaimpo (Grömping 2006). The 'pmvd' calculates a weighted average of sequential $\mathrm{R}^{2}$-values over all possible models. To account for spatial autocorrelation, we calculated SAR models and removed the spatial signal of the fitted values from the response variable. Logtransformed species richness excluding the spatial signal entered the calculations of relative importance as response variable in linear models (Belmaker and Jetz 2011). We multiplied the obtained relative proportions (hereafter proportional $\mathrm{R}_{\text {pmvd }}$ ) by the SAR model $\mathrm{R}^{2}$ values in order to get the absolute fraction of the multi-predictor $\mathrm{R}^{2}$ explained by a particular variable (hereafter $\mathrm{R}_{\mathrm{pmvd}}^{2}$ ).

To analyze potential interactions between isolation and other predictors, we calculated sequences of 303 multipredictor models along all islands ordered by area, temperature, precipitation, or elevational range, using data subsets comprising one third of the islands each, e.g. starting with the 151 smallest and ending with the largest islands. In order to show the relative importance of the isolation metrics along the environmental gradients, we calculated the proportional $\mathrm{R}_{\text {pmvd }}^{2} 95 \%$ confidence intervals of a null model for 151 randomly selected islands were calculated from 1000 permutations. Relative importance of the isolation metrics within geologic subsets was calculated and compared to null models accordingly.

\section{Results}

\section{Patterns of isolation}

The islands studied represent a wide range of isolation. Distance to the mainland $\left(\mathrm{D} 1 \mathrm{~b}_{\mathrm{m}}\right)$ ranged from $<100 \mathrm{~m}$ 

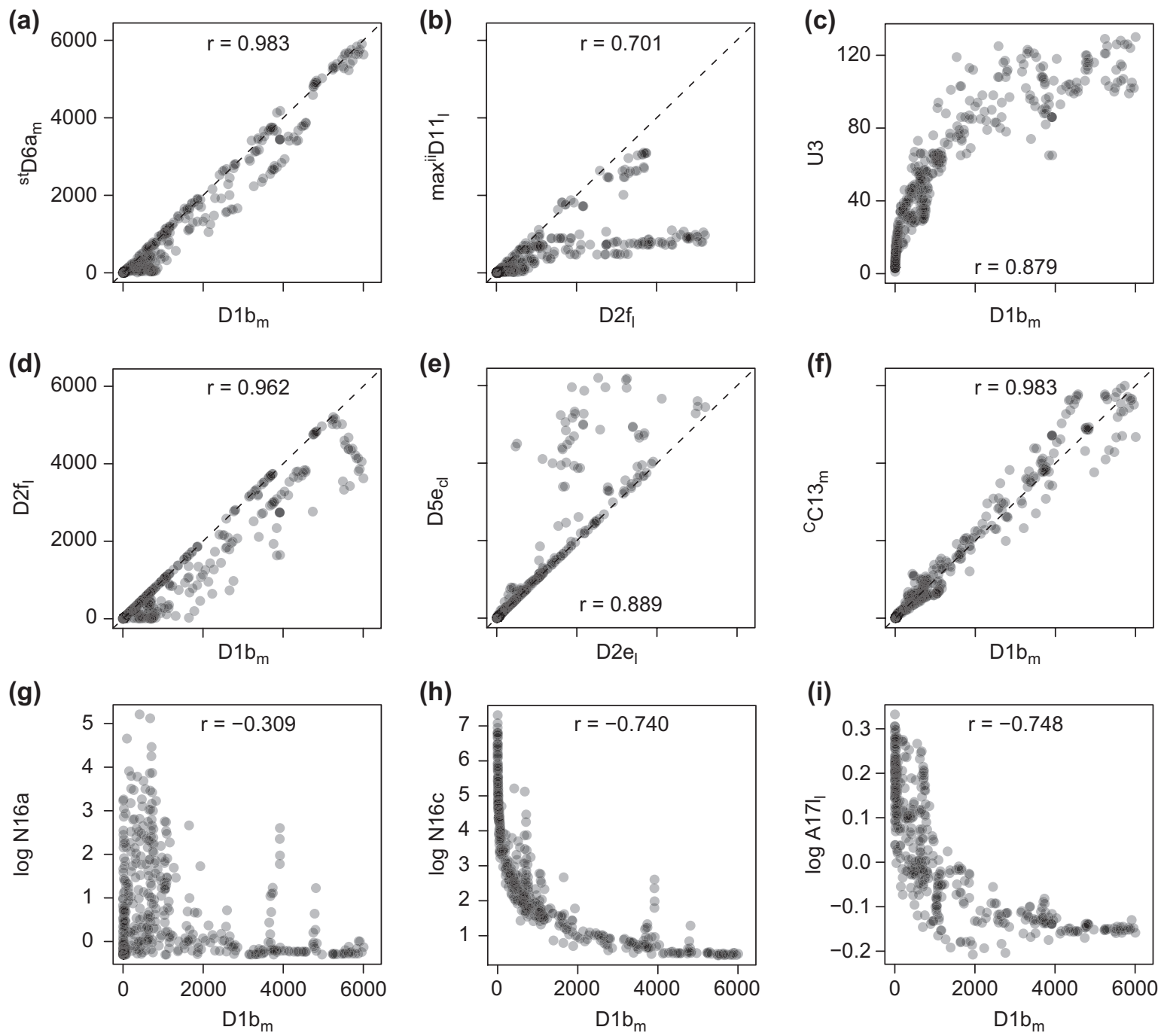

Figure 2. Selected relationships among metrics, illustrating the complexity of quantifying island isolation. All Pearson correlations (r) are significant at $\mathrm{p}<0.001$. Dashed lines indicate isometric lines. Metrics abbreviated with a D are geographic or weighted distances in $\mathrm{km}$. Others are dimensionless. See Fig. 1 and Table 1 for detailed explanation and metric abbreviations.

(Curtis Island, Australia) to $>6000 \mathrm{~km}$ (e.g. Rapa Iti, French Polynesia; median $=663.1 \mathrm{~km}$ ). The various isolation metrics show a high degree of collinearity. While some metrics were perfectly correlated, others were less closely related (lowest correlation: $\mathrm{max}{ }^{\mathrm{ii}} \mathrm{D} 8_{\mathrm{m}}$ and ${ }^{\mathrm{W}} \mathrm{C} 12_{\mathrm{m}}, \mathrm{r}=0.55$; Supplementary material Appendix 3). The relationships among some metrics are governed by simple geometric constraints (Fig. 2). For example, simple stepping stone distances $\left({ }^{\mathrm{st}} \mathrm{D} 6_{\mathrm{m}},{ }^{\mathrm{st}} \mathrm{D} 9_{\mathrm{l}}, \mathrm{max}^{\mathrm{ii}} \mathrm{D} 8_{\mathrm{m}}, \mathrm{max} \mathrm{D} 11_{1}\right)$ can only be shorter than or equal to the respective straight-line distances (D1, $\mathrm{D} 2$; Fig. 2a-b). The same holds true for distances to a landmass $\left(\mathrm{D} 2_{1}, \mathrm{D} 5_{\mathrm{cl}},{ }^{\text {,t }} \mathrm{D} 9_{\mathrm{l}}\right.$, $\left.{ }^{\mathrm{stM}} \mathrm{D} 10_{1}\right)$ compared to distances to the mainland (Fig. 2d). In contrast, distances to climatically similar areas can only be equal to or longer than distances disregarding climatic similarity (Fig. 2e). Distances taking into account wind or ocean currents may be shorter or longer than simple straight-line distances, while deviations from straight distances increase with distance (Fig. 2f). Metrics accounting for the landmass area surrounding an island (N16, A17 $)$ are nonlinearly and less strongly related to distance metrics (Fig. $2 \mathrm{~g}-\mathrm{i}$ ).

\section{Best metric variations}

For each isolation metric, we identified the best variation according to the spatial multi-predictor model AIC (Table 2; see Supplementary material Appendix 4 for SAR model results for all metric variations). The distance from the island coast to the mainland coast $\left(\mathrm{D} 1 \mathrm{~b}_{\mathrm{m}}\right)$ did not perform better than the respective distance from the mass centroid $\left(\mathrm{D} 1 \mathrm{a}_{\mathrm{m}}\right)$. Model fits of the distance to a source landmass improved with increasing minimum area thresholds of the landmass, reaching a maximum at $100000 \mathrm{~km}^{2}$ for the minimum area of any landmass $\left(\mathrm{D} 2 \mathrm{f}_{\mathrm{l}}\right)$ and $10000 \mathrm{~km}^{2}$ for climatically similar landmasses (D5e $\mathrm{e}_{\mathrm{c}}$; Fig. 3a). The distance to a landmass of a certain minimum size defined as a multiple of the target island area did not gain strong statistical support $\left(\mathrm{D} 2 \mathrm{~g}_{\mathrm{l}}-\mathrm{D} 2 \mathrm{p}_{\mathrm{l}}\right)$. The stepping stone distance on a minimum inter-island distance path was best represented by the length of the path itself $\left.{ }^{\mathrm{stM}} \mathrm{D} 7 \mathrm{~b}_{\mathrm{m}},{ }^{\mathrm{stM} M} \mathrm{D} 10 \mathrm{~b}_{1}\right)$. Weighting of the path length by the number or area of the stepping stones did not improve model fits. The original neighbour index did 
Table 2. Model fits of spatial simultaneous autoregressive models (SAR) with the $\log _{10}$-transformed number of vascular plant species on 453 islands as response variable and different isolation metrics as explanatory variables. The first model includes no isolation metrics, but only island area, temperature, precipitation, elevational range and geology, and is included for comparison. All other models include one isolation metric, either as a single predictor $\left(\mathrm{r}^{2}\right)$ or in a multi-predictor model including also island area, temperature, precipitation, elevational range and geology $\left(\mathrm{R}^{2}\right) . \mathrm{r}_{\mathrm{sp}}^{2}$ and $\mathrm{R}_{\mathrm{sp}}^{2}$ accounting for spatial autocorrelation are shown in parentheses. Except for $\mathrm{A} 17 \mathrm{I}_{\mathrm{l}}$ and $\mathrm{N} 16 \mathrm{c}$ all single predictor relationships are negative. For multi-predictor models, $\triangle \mathrm{AIC}$ was calculated as the difference from the best model $(\mathrm{AIC}=121.8)$. P-values in the multi-predictor models refer to estimates of the respective isolation metric. $R^{2}$ pmvd shows the absolute contribution of the respective isolation metric to the full model fit $\left(R^{2}\right)$. See Fig. 1 and Table 1 for metric abbreviations. Significance: $* * *(p<0.001)$.

\begin{tabular}{|c|c|c|c|c|c|c|}
\hline \multirow[b]{2}{*}{ Isolation metric } & \multicolumn{2}{|c|}{ Single-predictor models } & \multicolumn{4}{|c|}{ Multi-predictor models } \\
\hline & $r^{2}\left(r_{s p}^{2}\right)$ & $\mathrm{p}$ & $R^{2}\left(R_{s p}^{2}\right)$ & $\Delta \mathrm{AIC}$ & $\mathrm{P}$ & $\mathrm{R}_{\mathrm{pmvd}}^{2}$ \\
\hline- & - & - & $0.712(0.829)$ & 97.0 & - & - \\
\hline $\mathrm{D} 1 \mathrm{a}_{\mathrm{m}}$ & $0.240(0.489)$ & $* * *$ & $0.786(0.851)$ & 29.3 & $* * *$ & 0.152 \\
\hline $\mathrm{D} 2 \mathrm{f}_{\mathrm{l}}$ & $0.264(0.499)$ & $* * *$ & $0.786(0.852)$ & 26.7 & $* * *$ & 0.158 \\
\hline U3 & $0.231(0.493)$ & $* * *$ & $0.795(0.856)$ & 15.9 & $* * *$ & 0.151 \\
\hline $\mathrm{D} 4 \mathrm{c}_{\mathrm{m}}$ & $0.262(0.498)$ & $* * *$ & $0.776(0.845)$ & 49.8 & $* * *$ & 0.111 \\
\hline $\mathrm{D} 5 \mathrm{e}_{\mathrm{cl}}$ & $0.299(0.513)$ & $* * *$ & $0.800(0.856)$ & 14.7 & $* * *$ & 0.176 \\
\hline${ }^{\mathrm{st}} \mathrm{C} 6 \mathrm{~b}_{\mathrm{m}}$ & $0.253(0.498)$ & $* * *$ & $0.786(0.852)$ & 27.0 & $* * *$ & 0.158 \\
\hline${ }^{\mathrm{stM}} \mathrm{D} 7 \mathrm{~b}_{\mathrm{m}}$ & $0.249(0.492)$ & $* * *$ & $0.783(0.849)$ & 35.9 & $* * *$ & 0.133 \\
\hline $\max ^{\mathrm{ii} D 8_{\mathrm{m}}}$ & $0.138(0.475)$ & $* * *$ & $0.778(0.845)$ & 49.8 & $* * *$ & 0.074 \\
\hline stD9, & $0.264(0.497)$ & $* * *$ & $0.793(0.852)$ & 24.4 & $* * *$ & 0.161 \\
\hline${ }^{\operatorname{stM}} \mathrm{D} 10 \mathrm{~b}_{\mathrm{l}}$ & $0.230(0.485)$ & $* * *$ & $0.778(0.848)$ & 37.8 & $* * *$ & 0.122 \\
\hline $\max x^{i i D} 11_{1}$ & $0.180(0.483)$ & $* * *$ & $0.777(0.845)$ & 48.4 & $* * *$ & 0.096 \\
\hline${ }^{\mathrm{w}} \mathrm{C} 12_{\mathrm{m}}$ & $0.254(0.503)$ & $* * *$ & $0.763(0.846)$ & 44.8 & $* * *$ & 0.123 \\
\hline${ }^{\mathrm{C}} \mathrm{C} 13_{\mathrm{m}}$ & $0.251(0.501)$ & $* * *$ & $0.782(0.851)$ & 28.6 & $* * *$ & 0.152 \\
\hline${ }^{\mathrm{stw}} \mathrm{C} 14_{\mathrm{m}}$ & $0.273(0.502)$ & $* * *$ & $0.775(0.849)$ & 34.8 & $* * *$ & 0.146 \\
\hline${ }^{\mathrm{stC} C} 15_{\mathrm{m}}$ & $0.253(0.499)$ & $* * *$ & $0.787(0.853)$ & 22.3 & $* * *$ & 0.163 \\
\hline $\log \log$ N16c & $0.253(0.514)$ & $* * *$ & $0.786(0.852)$ & 28.9 & $* * *$ & 0.151 \\
\hline $\log A 17 I_{I}$ & $0.185(0.479)$ & $* * *$ & $0.807(0.861)$ & 0.0 & $* * *$ & 0.134 \\
\hline
\end{tabular}

(a)

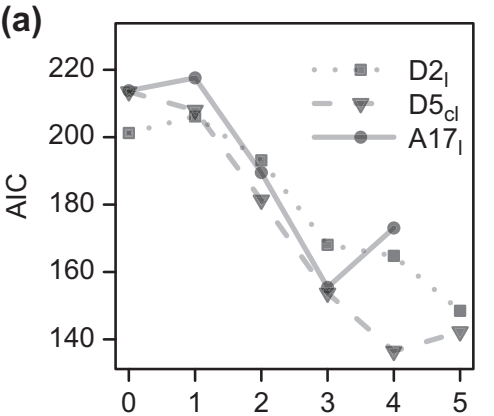

Area $\left(\log _{10} \mathrm{~km}^{2}\right) /$ radius $\left(\log _{10} \mathrm{~km}\right)$

(d)

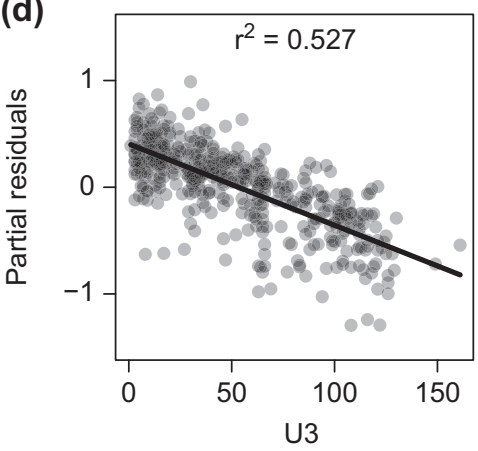

(b)

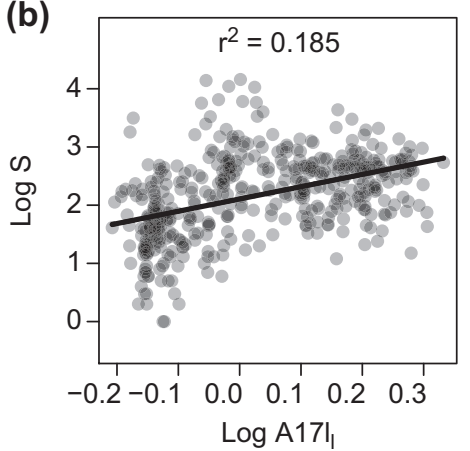

(e)

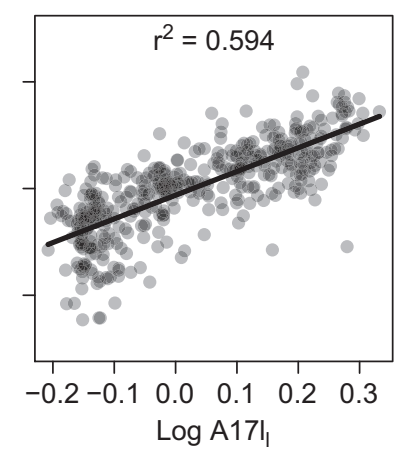

(c)

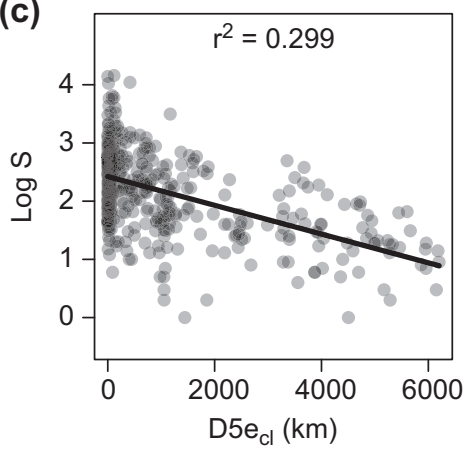

(f)

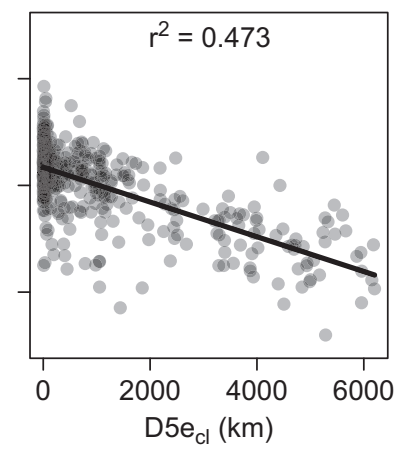

Figure 3. Selected relationships between the $\log _{10}$-transformed number of vascular plant species on 453 islands worldwide (log $S$ ) and different island isolation metrics. (a) Model fit (AIC) of spatial multi-predictor models including one metric variation of D2, D5 ${ }_{\mathrm{c}}$, or $\mathrm{A} 17$, and five other core predictors of island richness (area, temperature, precipitation, elevational range, geology). Metric variations differ in the minimum area of the considered potential source landmass (D2, $\mathrm{D} 5_{\mathrm{cl}}$ ) or the radius of the buffer in calculations of surrounding landmass proportions (A17). Note that lower AIC values indicate higher relative model support. (b-c) Simple linear relationships. (d-f) Partial residual plots for the three isolation metrics that produced highest model fits in the multi-predictor framework. The plots show the individual effects of the isolation metrics after effects of other predictors and spatial autocorrelation have been partialled out. See Fig. 1 and Table 1 for metric abbreviations. 
not contribute considerably to explaining species richness ( $\log$ N16a). However, the double log-transformed version of its variation accounting for all kinds of landmass performed significantly better $(\log \log$ N16c). The sum of the proportions of landmass within a buffer distance of 100,1000 and $10000 \mathrm{~km}\left(\mathrm{~A} 17 \mathrm{l}_{\mathrm{j}}\right)$ was the best metric variation of $\mathrm{A} 17_{1}$. The best variation considering the proportion of landmass within only one buffer zone used a radius of $1000 \mathrm{~km}$ (Fig. 3a).

\section{Species richness models}

Clear differences emerged from a comparison of the seventeen selected isolation metrics. Distances to landmasses yielded higher multi-predictor model fits than distances to the mainland (Table 2). This pattern was consistent across ordinary distances, distances accounting for climatic similarity and simple stepping stone distances. Simple stepping stone distances performed better than ordinary distances irrespective of the source landmass and whether wind or ocean currents were corrected for or not. Length and costs of the minimum inter-island distance path as well as the minimum inter-island distance did not yield strong statistical support. Consideration of prevailing winds did not improve model fits. Models accounting for ocean currents performed better than models based on unweighted distances when stepping stones were considered. The modified neighbour index (N16c) did not improve the model fit compared to the distance to mainland.

The overall best metric in a multi-predictor framework was the proportion of surrounding landmass, $\log A 17 l_{1}$ $(\mathrm{AIC}=121.8$; Fig. 3 e, Table 2). This model explained $86.1 \%$ of the variation. However, its contribution to overall $\mathrm{R}^{2}$ measured as $\mathrm{R}_{\text {pmvd }}^{2}$ was comparatively small $\left(\mathrm{R}_{\text {pmvd }}^{2}=\right.$ $0.134)$ due to a weak single-predictor relationship of the metric and species richness (Fig. 3b). Second best models according to AIC included the distance to climatically similar landmass $\left(\mathrm{D} 5 \mathrm{e}_{\mathrm{c}}\right)$ and the UNEP Isolation Index (U3; Fig. 3d, f). The strongest single-predictor relationship $\left(r^{2}=0.299\right)$ and relative importance $\left(\mathrm{R}_{\text {pmvd }}^{2}=0.176\right)$ were found for $\mathrm{D} 5 \mathrm{e}_{\mathrm{cl}}$ (Fig. 3c). These results are consistent with results from non-spatial models (Supplementary material Appendix 5).

Including more than one isolation metric in the multi-predictor models significantly improved model fits (Supplementary material Appendix 6). The model with the lowest AIC (81.5) included the proportion of surrounding landmass ( $\left.\mathrm{A} 17 \mathrm{l}_{1}\right)$, the distance to climatically similar landmass $\left(\mathrm{D} 5 \mathrm{e}_{\mathrm{cl}}\right)$ and the maximum inter-island distance $\left(\max { }^{\mathrm{ii}} \mathrm{D} 11_{1}\right)$. These metrics represent three different components of isolation, two different source pool concepts (Table 1$)$, and are only moderately collinear $(\mathrm{r}<0.7$; Supplementary material Appendix 3). Models including four isolation metrics did not perform better in terms of AIC. Adding second-order interactions between area and the three isolation metrics included in the best model further improved the model fit (AIC $=56.15$ after dropping the non-significant interaction between log-area and max $\left.{ }^{\mathrm{ii}} \mathrm{D} 11_{1}\right)$. Isolation was the second most important factor explaining species richness in all compared candidate models, explaining up to $23 \%$ of the variation in species richness. Only area showed a higher relative importance (Supplementary material Appendix 6).

\section{Species richness correlates in environmental subsets}

Species richness correlates of the strongest isolation metrics showed similar trends for island subsets along environmental gradients (Fig. 4). However, the effect of distance metrics on species richness was generally strongest for medium-sized islands, whereas the maximum influence of surrounding landmasses $\left(A 17 \mathrm{j}_{1}\right)$ was seen in small islands (Fig. 4a), contributing up to $60 \%$ of the explained variation. The contribution of all considered metrics decreased rapidly when including large islands $\left(>1000 \mathrm{~km}^{2}\right)$. The relative importance of isolation decreased with increasing mean annual temperature (Fig. 4b). Maximum contribution to explaining species richness, for all metrics, was found for low to medium annual precipitation and medium elevational range (Fig. 4c-d). Isolation was a much weaker correlate of species richness for continental than for oceanic islands and for volcanic islands than for atolls (Fig. 4e). Distance to climatically similar landmass (D5 ${ }_{\mathrm{cl}}$ ) was the most important metric for species richness on atolls. For other geologic categories no considerable differences among isolation metrics were found.

\section{Discussion}

We present the first comprehensive, comparative analysis of island isolation with broad geographic extent. The only other comparison of a wide variety of isolation metrics we are aware of was presented by Diver (2008), studying the relationship between isolation and richness of vascular plants on near-shore freshwater islets. We confirm previous findings that isolation is a strong predictor of species richness (Kalmar and Currie 2006). Single isolation metrics explained up to $17.6 \%$ of the variation in vascular plant diversity (distance to nearest climatically similar landmass area, $\mathrm{D} 5 \mathrm{e}_{\mathrm{cl}}$; Table 2). However, our study emphasizes that a variety of facets of isolation affect island colonization and the maintenance of established populations. Importantly, not a single metric alone accounted for all the variation. Rather, different aspects contributed to defining isolation as a driver of species richness.

Our results demonstrate that proximity to neighbouring large islands is an important driver of island species richness (D2 $\mathrm{f}_{\mid}, \mathrm{D} 5 \mathrm{e}_{\mathrm{c}}$; Table 2). This suggests that large islands, as well as continents, serve as major sources for colonization and maintenance of species richness. We also show that the absolute area of a potential source is more important than its size relative to the target island (D2g-p; Supplementary material Appendix 4). This lines up with theoretical expectations, as numbers of potentially immigrating species and propagules both increase with source area (MacArthur and Wilson 1967). Small islands are therefore less important sources of immigration, even for small target islands (Fig. 3a). However, the potential of a source depends on the island of interest and colonization depends 

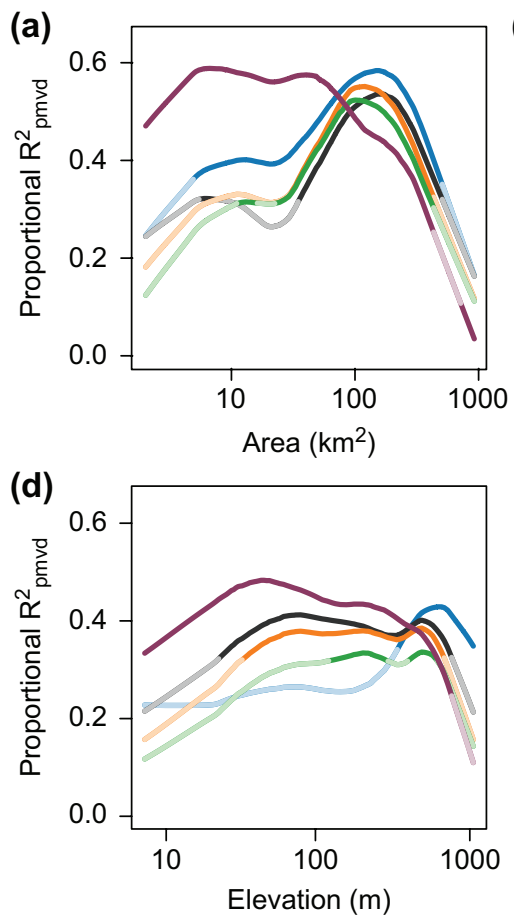

(b)

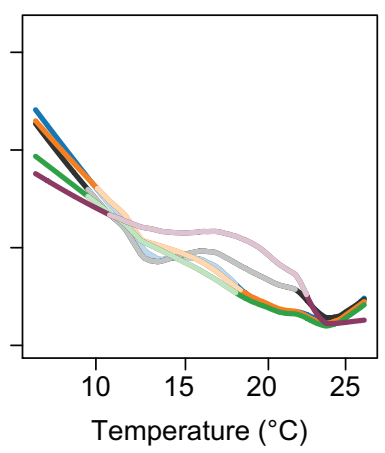

(e)

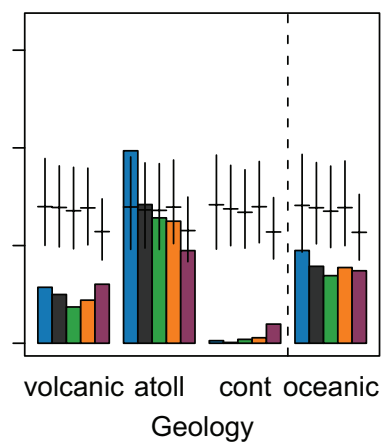

(c)

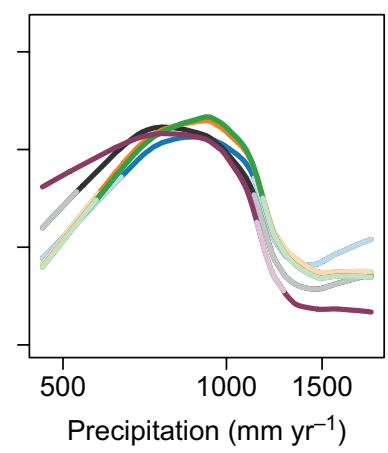

Isolation metrics

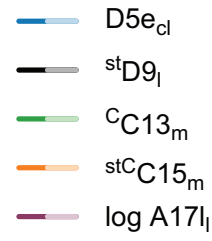

Figure 4. Interactions between isolation metrics and other core predictors of island richness. (a-d) Relative importance (proportional $\mathrm{R}_{\text {pmvd }}^{2}$ ) of the best isolation metrics among five isolation components shown for sequences of data subsets including one third of the entity of 453 islands. Proportional $\mathrm{R}_{\text {pmvd }}^{2}$-values were calculated based on simultaneous autoregressive models (SAR) of vascular plant species richness accounting for area, temperature, precipitation, elevational range, geology and the respective isolation metric. The data subsets were consecutively taken from the full data set ordered by (a) area, (b) temperature, (c) precipitation and (d) elevation. X-axes in $(\mathrm{a}-\mathrm{d})$ are shown in $\log _{10}$-scale and give the median values of the sorting variables. Parts of the lines not significantly different $(\mathrm{p}<0.05)$ from random draws of the same number of islands are shown in light shades. (e) Proportional contribution to overall $\mathrm{R}^{2}$ of isolation for islands of different geologic origin (oceanic islands comprise volcanic islands and atolls, cont - continental islands). Null model median and 95\% confidence intervals are indicated by black lines. See Fig. 1 and Table 1 for metric abbreviations.

on favourable environmental conditions (MacArthur and Wilson 1967, Steinbauer et al. 2012), making it more likely that islands receive colonizers from climatically similar areas. Additionally, continental refugia provide evidence that climatic barriers may modify isolation influencing migration and diversification (Willis and Whittaker 2000, Médail and Diadema 2009). To our knowledge, climate has not been considered in measurements of island isolation before, although it is clearly an important factor at a global scale. This hypothesis is supported by the strength of our metric using the distance to climatically similar landmasses (D5e $\mathrm{e}_{\mathrm{c}} ;$ Table 2). It is noteworthy that this simplistic metric significantly improved the fit of species richness models.

We found the strongest effect of isolation when measuring the proportion of surrounding landmass (A171, Fig. 3e), a metric that incorporates the distance to large landmasses, their area and their coastline shape (Fig. 1). This finding is consistent with Diver (2008) and indicates that not only the distance to but also the amount of available source area drives immigration rates. At a global scale, the proportion of landmass within large buffer distances (100-10000 km) were most important (Fig. 3a) highlighting the relevance of an island's position relative to very large landmasses. However, Diver's (2008) results, in which species richness was best explained by the landmass proportion within a $0.25 \mathrm{~km}$ buffer, suggest that the optimal buffer radius for measuring isolation depends on the spatial scale of the study.

The fact that stepping stone metrics consistently gained higher statistical support than straight distances (Table 2) strongly suggests that direct dispersal is not the only relevant immigration mechanism. Instead, it indicates that islands between target and source areas decrease isolation, and supports the hypothesis that island-hopping is an important mechanism (Whittaker and Fernández-Palacios 2007). For instance, spatially clustered island groups along edges of tectonic plates or above volcanic hotspots, such as the Kuriles or the Canaries, may make dispersal possible to islands far off the mainland for species not capable of extraordinary long-distance dispersal (compare Fig. 1a; Fernández-Palacios et al. 2011). When accounting for the two strongest metrics $\left(\mathrm{D} 5 \mathrm{e}_{\mathrm{cl}}\right.$ and $\left.\mathrm{A} 17 \mathrm{l}_{\mathrm{l}}\right)$, the maximum inter-island distance (max $\left.\mathrm{D} 11_{1}\right)$ emerged as a significant predictor (Supplementary material Appendix 6). The variation additionally explained by max ${ }^{\text {if }} \mathrm{D} 11_{1}$ might be attributed to species with restricted long-distance dispersal abilities, for which the chance of immigration depends on the maximum distance to cross.

We did not find consistent support for metrics including prevailing wind and ocean currents although these factors are assumed to strongly affect dispersal (Muñoz et al. 2004, Cook and Crisp 2005). We used ten-year means of zonal and horizontal velocities for the calculation of prevailing 
directions, which blurred seasonality. Generally, rare extremes, such as tropical cyclones, are expected to support long-distance dispersal (Bullock and Clarke 2000). In contrast, Tackenberg et al. (2003) argued that low horizontal wind speeds enhance the dispersal potential. However, currents may change drastically over the relevant time scales of island emergence and colonization. Present day conditions might therefore be weak predictors of past immigration events (Ali and Huber 2010, Fernández-Palacios et al. 2011). Our results suggest that currents in general and ocean currents in particular ( ${ }^{\mathrm{stC}} \mathrm{C} 15_{\mathrm{m}}$; Table 2) can affect insular species richness. But due to methodological constraints, we are careful to draw final conclusions.

Another potential source of uncertainty is the similarity of some of our isolation metrics: the presented metrics showed a considerable degree of collinearity (Supplementary material Appendix 3). Their similarity made differences in their predictive power appear small and hampered direct inferences about their relative importance and biogeographic role. However, our results were consistent among different models, highly collinear metrics were not included in single models, and metric comparisons were based on model fit, which should be independent of collinearity (Graham 2003).

Another factor to consider in interpreting our results is that isolation effects may interact with species-specific dispersal properties (Lomolino 1982). Water-dispersed species should be affected by ocean currents, whereas winds should strongly affect wind-dispersed species. Stepping stones could be of particular importance for dispersal by birds and of minor importance for species passively dispersed by wind or water (MacArthur and Wilson 1967). Isolation in general may be of minor importance for species with very light, wind dispersed diaspores, such as ferns, which are relatively speciose on islands (Kreft et al. 2010, but see Vargas et al. 2012). Our analysis for vascular plants can only provide a generalized picture, but future comparative studies could shed light on trait-specific patterns.

Just as indicated for wind and ocean currents, our correlative approach in general was limited by the fact that the explanatory variables tested represented only contemporary conditions (compare McGlone 1996). We did not include historical isolation (compare Hausdorf and Hennig 2005) or island age due to a lack of data. Hence, we had to disregard important factors such as the developmental state of islands, the elapsed time available for cladogenesis and changing isolation scenarios due to sea level changes, volcanism and tectonic drift. We show that contemporary isolation is more important for oceanic than for continental islands (Fig. 4e) possibly reflecting connections of continental islands to continents in the past (Whittaker and Fernández-Palacios 2007). In addition, oceanic islands show varying rates of immigration, speciation and extinction over time when emerging through volcanic activity or submerging by erosion (Whittaker et al. 2008). On a geologic time scale, they are relatively ephemeral landmasses. Stepping stone metrics, for instance, might therefore be biased as a result of ignoring submerged islands that were crucial for past immigrations (for reconstruction of, e.g. Palaeo-Macaronesia see Fernández-Palacios et al. 2011). Furthermore, not only may the isolation from a proper source pool change, but also the properties of the source itself (e.g. total number of species, potential colonizers) may be subject to significant changes over relevant times due to geologic and climatic changes (Fernández-Palacios et al. 2011, Zobel et al. 2011). Given these inevitable limitations, it is remarkable that our models explained up to $87 \%$ of the variation in vascular plant species richness and that the additive effects of three metrics of contemporary isolation contributed 23\% (Supplementary material Appendix 6).

Despite not having included evolutionary processes in our analysis, we can infer that cladogenesis on large islands may counteract the negative effect of isolation on species richness. The probability of speciation increases with area (Heaney 2000, Kisel and Barraclough 2010). Given enough time, large isolated islands should approach their carrying capacity via cladogenesis even if colonization events are rare (Whittaker et al. 2008). Isolation is therefore expected to be less important for species richness on very large islands, which was confirmed by our subset analysis (Fig. 4a). Small to medium-sized islands that hold unstable populations, however, could be affected considerably by isolation. Due to source and sink dynamics (Pulliam 1988) and complex metapopulation systems (Hanski and Gilpin 1991), species on small and less isolated islands consist partly of populations that are not viable without steady immigration of individuals ('rescue effect'; Brown and Kodric-Brown 1977). Accordingly, we found that particularly the proportion of surrounding landmass area $\left(A 17 l_{1}\right)$ has a great influence on species richness on small islands (Fig. 4a) possibly via its negative effects on extinction rates. In addition to area, temperature and precipitation influenced isolation effects on species richness (Fig. 4b, c). This suggests that isolation might be more important on islands where overall carrying capacity is low due to low productivity (Wright 1983) and where cladogenesis is less likely due to low temperatures (Allen et al. 2002). Besides area and climate, elevational range (as surrogate of environmental heterogeneity) influenced the effect of isolation on species richness (Fig. 4d). On heterogeneous, isolated islands, cladogenesis may be promoted by a comparatively empty niche space (Heaney 2000). Furthermore, diversification rates can be expected to increase with altitude due to a greater climatic isolation of high elevation ecosystems (Steinbauer et al. 2012). Our results add to this by showing a decrease of the influence of isolation on richness with increasing elevational range for the proportion of surrounding landmass area (A17l $\mathrm{l}_{1}$; Fig. $4 \mathrm{~d}$ ).

We conclude that isolation is comprised of multiple components that cannot be captured in a single metric. In fact, a range of different immigration mechanisms influence island biogeographic patterns. The ordinary distance to the nearest mainland is an adequate and simple-tocalculate measure. However, accounting for stepping stones, large islands as source areas, climatic similarity and the area of surrounding landmasses increases the explanatory power of isolation for species richness. At a global scale, the proportional landmass within certain buffer distances around an island is the best metric $\left(\mathrm{A} 17 \mathrm{l}_{1}\right)$. The effect of isolation depends on the degree of isolation of the considered system and the dispersal mode of the studied taxa (Lomolino 1982) as well as on abiotic factors. We therefore 
suggest choosing metrics for a study system on an empirical basis. The provided metrics (Supplementary material Appendix 9) may be useful not only in analyses of species richness but also of other biogeographic patterns such as gene flow and genetic diversity (Slatkin 1993), speciation (Kisel and Barraclough 2010), endemism (Bunnefeld and Phillimore 2012), phylogeography (Cook and Crisp 2005), species composition and turnover (Hausdorf and Hennig 2005), community structure (Santos et al. 2011) or species traits (Meiri et al. 2005). Finally, it would be useful to test the isolation metrics in other isolated or fragmented systems.

Acknowledgements - We thank the members of the Biodiversity, Macroecology and Conservation Biogeography Group as well as Daniel W. Carstensen for feedback on an early version of the manuscript. We are very grateful to Joaquín Hortal for providing very insightful comments on the manuscript. We thank Rodrigo Soria Auza and Olaf Conrad for assistance with NCEP/NCAR wind data. This study was supported by the German Research Council (DFG) in the scope of the Excellence Initiative within the Free Floater Programme at the Univ. of Göttingen.

\section{References}

Abbott, I. 1974. Numbers of plant, insect and land bird species on nineteen remote islands in the Southern Hemisphere. - Biol. J. Linn. Soc. 6: 143-152.

Abbott, I. 1978. Factors determining the number of land bird species on islands around south-western Australia. - Oecologia 33: 221-233.

Ali, J. R. and Huber, M. 2010. Mammalian biodiversity on Madagascar controlled by ocean currents. - Nature 463: 653-656.

Allen, A. P. et al. 2002. Global biodiversity, biochemical kinetics, and the energetic-equivalence rule. - Science 297: $1545-1548$.

Alsos, I. G. et al. 2007. Frequent long-distance plant colonization in the changing Arctic. - Science 316: 1606-1609.

Bellemain, E. and Ricklefs, R. 2008. Are islands the end of the colonization road? - Trends Ecol. Evol. 23: 461-468.

Belmaker, J. and Jetz, W. 2011. Cross-scale variation in species richness-environment associations. - Global Ecol. Biogeogr. 20: 464-474.

Bivand, R. et al. 2011. spdep: spatial dependence: weighting schemes, statistics and models. $-<$ http://CRAN.R-project. org $/$ package $=$ spdep $>$.

Borges, P. A. V. and Hortal, J. 2009. Time, area and isolation: factors driving the diversification of Azorean arthropods. - J. Biogeogr. 36: 178-191.

Boyer, A. G. and Jetz, W. 2010. Biogeography of body size in Pacific island birds. - Ecography 33: 369-379.

Brown, J. H. and Kodric-Brown, A. 1977. Turnover rates in insular biogeography: effect of immigration on extinction. - Ecology 58: 445-449.

Bullock, J. M. and Clarke, R. T. 2000. Long distance seed dispersal by wind: measuring and modelling the tail of the curve. - Oecologia 124: 506-521.

Bunnefeld, N. and Phillimore, A. B. 2012. Island, archipelago and taxon effects: mixed models as a means of dealing with the imperfect design of nature's experiments. - Ecography 35: 15-22.

Burnham, K. P. and Anderson, D. R. 2002. Model selection and multimodel inference: a practical information-theoretic approach. - Springer.
Cardoso, P. et al. 2010. Drivers of diversity in Macaronesian spiders and the role of species extinctions. - J. Biogeogr. 37: 1034-1046.

Carroll, S. P. et al. 2007. Evolution on ecological time-scales. - Funct. Ecol. 21: 387-393.

Case, T. J. 1975. Species numbers, density compensation, and colonizing ability of lizards on islands in the Gulf of California. - Ecology 56: 3-18.

Chown, S. L. et al. 1998. Ecological biogeography of Southern Ocean islands: species area relationships, human impacts, and conservation. - Am. Nat. 152: 562-575.

Cody, M. L. 2006. Plants on islands: diversity and dynamics on a continental archipelago. - Univ. of California Press.

Cook, L. G. and Crisp, M. D. 2005. Directional asymmetry of long-distance dispersal and colonization could mislead reconstructions of biogeography. - J. Biogeogr. 32: 741-754.

Crawley, M. J. 2007. The R book. - Wiley.

Dahl, A. 2004. United Nations Environment Programme Island Directory. $\quad-<$ http://islands.unep.ch/isldir.htm $>$ accessed 10 October 2010.

Díaz-Pérez, A. et al. 2008. Multiple colonizations, in situ speciation, and volcanism-associated stepping-stone dispersals shaped the phylogeography of the Macaronesian red fescues (Festuca L., Gramineae). - Syst. Biol. 57: 732-749.

Diver, K. C. 2008. Not as the crow flies: assessing effective isolation for island biogeographical analysis. - J. Biogeogr. 35: 1040-1048.

Dormann, C. F. et al. 2007. Methods to account for spatial autocorrelation in the analysis of species distributional data: a review. - Ecography 30: 609-628.

Fernández-Palacios, J. M. et al. 2011. A reconstruction of Palaeo-Macaronesia, with particular reference to the long-term biogeography of the Atlantic island laurel forests. - J. Biogeogr. 38: 226-246.

Garb, J. E. and Gillespie, R. G. 2006. Island hopping across the central Pacific: mitochondrial DNA detects sequential colonization of the Austral Islands by crab spiders (Araneae: Thomisidae). - J. Biogeogr. 33: 201-220.

Gilpin, M. E. 1980. The role of stepping-stone islands. - Theor. Popul. Biol. 17: 247-253.

Graham, M. H. 2003. Confronting multicollinearity in ecological multiple regression. - Ecology 84: 2809-2815.

Grömping, U. 2006. Relative importance for linear regression in R: the package relaimpo. - J. Stat. Softw. 17: 1-27.

Hanski, I. and Gilpin, M. E. 1991. Metapopulation dynamics: brief history and conceptual domain. - Biol. J. Linn. Soc. 42: 3-16.

Harbaugh, D. T. and Baldwin, B. G. 2007. Phylogeny and biogeography of the sandalwoods (Santalum, Santalaceae): repeated dispersals throughout the Pacific. - Am. J. Bot. 94: 1028-1040.

Hausdorf, B. and Hennig, C. 2005. The influence of recent geography, palaeogeography and climate on the composition of the fauna of the central Aegean Islands. - Biol. J. Linn. Soc. 84: 785-795.

Heaney, L. R. 2000. Dynamic disequilibrium: a long-term, large-scale perspective on the equilibrium model of island biogeography. - Global Ecol. Biogeogr. 9: 59-74.

Hijmans, R. J. et al. 2005. Very high resolution interpolated climate surfaces for global land areas. - Int. J. Climatol. 25: 1965-1978.

Hijmans, R. J. et al. 2009. GADM database of Global Administrative Areas, ver. 1. $-<$ www.gadm.org $>$ accessed 16 June 2010.

Jarvis, A. et al. 2008. Hole-filled seamless SRTM data version 4. - International Centre for Tropical Agriculture (CIAT), $<$ http://srtm.csi.cgiar.org > accessed 16 June 2010.

Johnson, M. P. and Simberloff, D. S. 1974. Environmental determinants of island species numbers in the British Isles. - J. Biogeogr. 1: 149-154. 
Kalmar, A. and Currie, D. J. 2006. A global model of island biogeography. - Global Ecol. Biogeogr. 15: 72-81.

Keppel, G. et al. 2009. Changing perspectives on the biogeography of the tropical South Pacific: influences of dispersal, vicariance and extinction. - J. Biogeogr. 36: 1035-1054.

Kier, G. et al. 2009. A global assessment of endemism and species richness across island and mainland regions. - Proc. Natl Acad. Sci. USA 106: 9322.

Kisel, Y. and Barraclough, T. G. 2010. Speciation has a spatial scale that depends on levels of gene flow. - Am. Nat. 175: 316-334.

Kissling, W. D. and Carl, G. 2008. Spatial autocorrelation and the selection of simultaneous autoregressive models. - Global Ecol. Biogeogr. 17: 59-71.

Kistler, R. et al. 2001. The NCEP-NCAR 50-year reanalysis: monthly means CD-ROM and documentation. - Bull. Am. Meteorol. Soc. 82: 247-268.

Kreft, H. et al. 2008. Global diversity of island floras from a macroecological perspective. - Ecol. Lett. 11: 116-127.

Kreft, H. et al. 2010. Contrasting environmental and regional effects on global pteridophyte and seed plant diversity. - Ecography 33: 408-419.

Lomolino, M. V. 1982. Species-area and species-distance relationships of terrestrial mammals in the Thousand Island Region. - Oecologia 54: 72-75.

Lomolino, M. V. and Brown, J. H. 2009. The reticulating phylogeny of island biogeography theory. - Q. Rev. Biol. 84: 357-390.

Losos, J. B. and Schluter, D. 2000. Analysis of an evolutionary species-area relationship. - Nature 408: 847-850.

MacArthur, R. H. and Wilson, E. O. 1967. The theory of island biogeography. - Princeton Univ. Press.

McGlone, M. S. 1996. When history matters: scale, time, climate and tree diversity. - Global Ecol. Biogeogr. Lett. 5: 309-314.

McMaster, R. T. 2005. Factors influencing vascular plant diversity on 22 islands off the coast of eastern North America. - J. Biogeogr. 32: 475-492.

Médail, F. and Diadema, K. 2009. Glacial refugia influence plant diversity patterns in the Mediterranean Basin. - J. Biogeogr. 36: 1333-1345.

Meiri, S. et al. 2005. Area, isolation and body size evolution in insular carnivores. - Ecol. Lett. 8: 1211-1217.

Menemenlis, D. et al. 2008. ECCO2: high resolution global ocean and sea ice data synthesis. - Mercator Ocean Q. Newslett. 31: 13-21.

Muńoz, J., et al. 2004. Wind as a long-distance dispersal vehicle in the southern hemisphere. - Science 304: 1144-1147.

Supplementary material (Appendix E7669 at <www. oikosoffice.lu.se/appendix $>$ ). Appendix 1-10.
Price, J. P. 2004. Floristic biogeography of the Hawaiian Islands: influences of area, environment and paleogeography. - J. Biogeogr. 31: 487-500.

Pulliam, H. R. 1988. Sources, sinks, and population regulation. - Am. Nat. 5: 652-661.

Santos, A. M. C. et al. 2010. Assessing the reliability of biodiversity databases: identifying evenly inventoried island parasitoid faunas (Hymenoptera: Ichneumonoidea) worldwide. - Insect Conserv. Divers. 3: 72-82.

Santos, A. M. C. et al. 2011. Species pool structure determines the level of generalism of island parasitoid faunas. - J. Biogeogr. 38: $1657-1667$.

Slatkin, M. 1993. Isolation by distance in equilibrium and nonequilibrium populations. - Evolution 47: 264-279.

Steinbauer, M. J. et al. 2012. Increase of island endemism with altitude - speciation processes on oceanic islands. - Ecography 35: 23-32.

Stuessy, T. F. et al. 2006. Anagenetic evolution in island plants. - J. Biogeogr. 33: 1259-1265.

Tackenberg, O. et al. 2003. Assessment of wind dispersal potential in plant species. - Ecol. Monogr. 73: 191-205.

Taylor, R. 1987. The geometry of colonization: 1. Islands. - Oikos 48: 225-231.

Thornton, I. W. B. 1967. The measurement of isolation on archipelagos, and its relation to insular faunal size and endemism. - Evolution 21: 842-849.

Vargas, P. et al. 2012. Colonization of the Galápagos Islands by plants with no specific syndromes for long-distance dispersal: a new perspective. - Ecography 35: 33-43.

Whitehead, D. R. and Jones, C. E. 1969. Small islands and the equilibrium theory of insular biogeography. - Evolution 23: $171-179$.

Whittaker, R. J. et al. 2001. Scale and species richness: towards a general, hierarchical theory of species diversity. - J. Biogeogr. 28: 453-470.

Whittaker, R. J. and Fernández-Palacios, J. M. 2007. Island biogeography: ecology, evolution, and conservation. - Oxford Univ. Press.

Whittaker, R. J. et al. 2008. A general dynamic theory of oceanic island biogeography. - J. Biogeogr. 35: 977-994.

Willis, K. J. and Whittaker, R. J. 2000. The refugial debate. - Science 287: 1406-1407.

Wright, D. H. 1983. Species-energy theory: an extension of species-area theory. - Oikos 41: 496-506.

Zobel, M. et al. 2011. The formation of species pools: historical habitat abundance affects current local diversity. - Global Ecol. Biogeogr. 20: 251-259. 